First Peoples Child \& Family Review

An Interdisciplinary Journal Honouring the Voices, Perspectives, and Knowledges of First Peoples through Research, Critical Analyses, Stories, Standpoints and Media Reviews

\title{
Youth Custody: Exercising Our Rights and Responsibilities to Indigenous Youth
}

\section{Molly Wickham}

Volume 5, Number 1, 2010

URI: https://id.erudit.org/iderudit/1069062ar

DOI: https://doi.org/10.7202/1069062ar

See table of contents

Publisher(s)

First Nations Child and Family Caring Society of Canada

ISSN

1708-489X (print)

2293-6610 (digital)

Explore this journal

Cite this article

Wickham, M. (2010). Youth Custody: Exercising Our Rights and Responsibilities to Indigenous Youth. First Peoples Child \& Family Review, 5(1), 57-66.

https://doi.org/10.7202/1069062ar

\section{Article abstract}

Colonization is a common experience amongst Indigenous youth; the effects of which have contributed to an over representation of Indigenous youth in correctional facilities in British Columbia (B.C). Placing youth in custody violates Indigenous values and child rearing practices and advances internalized oppression by focusing on the individual as the problem. In order to counter these effects, Indigenous youth in custody require education and engagement in the areas of colonization and decolonization. This paper discusses how the youth justice system in B.C fails Indigenous youth and how one group of young Indigenous people have acted upon their responsibility to support their incarcerated brothers and sisters.
This document is protected by copyright law. Use of the services of Erudit (including reproduction) is subject to its terms and conditions, which can be viewed online.

https://apropos.erudit.org/en/users/policy-on-use/ 


\title{
Youth Custody: Exercising our Rights and Responsibilities to Indigenous Youth
}

\author{
Molly Wickham ${ }^{a}$
}

\begin{abstract}
a BA Sociology- Social Justice, MA Candidate - Indigenous Governance, University of Victoria.

Hadih, I am the daughter of June Wickham, granddaughter of Emily Isaac, the great granddaughter of Julie and Paddy Isaac, and a member of the Gitdumden clan of the Wet'suwet'en Nation. I have been a visitor on Coast and Straights Salish territory while I have journeyed through my education. During my time here I have committed myself to a high standard of academic achievement and community involvement. I believe it is my duty as a visitor to contribute to the local community through my work with youth. I have been involved with high risk youth for the last five years, and youth in custody for the last three years. My education and Indigenous values enforce the necessity to support highly vulnerable Indigenous youth against colonial attacks and abuses. I plan to return to my community to support Wet'suwet'en youth and advance the assertion of a traditional Wet'suwet'en form of governance through our clan system. Based on our clan system I recognize the importance of family and will work towards strengthening Indigenous families to enhance cultural transmission. I attribute my successes as a Wet'suwet'en woman to my family, my ancestors, and the young ones who guide me in my work.
\end{abstract}

\section{Introduction}

To be sure, the youth 'justice' system in Canada, particularly in British Columbia (BC) does not provide justice for Indigenous people. To accurately describe the colonial system that I am referring to, I will refer to the Youth Justice System as the injustice system. The current Canadian injustice system is based on European values and serves current colonial agendas. Central to the discussion of any colonial institution is colonialism and its effects. It is through a discussion of colonialism that we can analyze the detrimental cost of incarceration on our youth. Indigenous youth have bared the brunt of colonialism's wrath for far too long, through the Residential School Era, the 'Sixties Scoop' and the child welfare system. Currently, various initiatives are being implemented within the injustice system,

Questions or correspondence concerning this article may be addressed to:

Email:mwickham@uvic.ca

\begin{abstract}
Colonization is a common experience amongst Indigenous youth; the effects of which have contributed to an over representation of Indigenous youth in correctional facilities in British Columbia (B.C). Placing youth in custody violates Indigenous values and child rearing practices and advances internalized oppression by focusing on the individual as the problem. In order to counter these effects, Indigenous youth in custody require education and engagement in the areas of colonization and decolonization. This paper discusses how the youth justice system in B.C fails Indigenous youth and how one group of young Indigenous people have acted upon their responsibility to support their incarcerated brothers and sisters.
\end{abstract}

however, most of these initiatives are focused on preventative measures and integrated systems of Indigenous and mainstream justice. Although preventative measures are vital to the survival of Indigenous nations, Indigenous philosophy demands that no young people are left to be terrorized and abused, a goal that is not being adequately met, as I will discuss. While I recognize the inherent risk of attempting to work within a system of domination, I propose the need to focus attention on the decolonization of Indigenous youth in custody in British Columbia, without engaging in a controlled relationship with the federal or provincial government. It is vital that Indigenous people continue to attack the legitimacy of the colonial injustice system; however, it is also necessary for Indigenous communities to focus on Indigenous youth that are currently in correctional facilities. Although $\mathrm{BC}$ has one of the lowest youth incarceration rates, this also contributes to less cultural programming and involvement with Indigenous communities than elsewhere in Canada. Cultural transmission is lacking in BC correctional facilities, and it is necessary for Indigenous people to assert control in this area. By asserting control over the cultural transmission of our stolen children, Indigenous people advance the decolonization process while promoting the survival of our 
young people. The goal is to decolonize cultural programming for Indigenous youth in custody in B.C. To explore this issue, I begin by examining the current condition of incarcerated Indigenous youth and the colonial agenda. Through this examination, I will analyze the existing cultural programming and their effectiveness in relation to Indigenous law and values. As discussed below, it is imperative that decolonization processes are build upon traditional principles like respect and interconnectedness. It is from here that a framework for reconnecting to incarcerated Indigenous youth can occur in a meaningful way that benefits both youth and cultural transmission in general. I use a new program of decolonizing youth in custody as an example of the decolonization that can and must take place; justice must occur in new and creative ways.

In Wasáse (2005), Taiaiake Alfred describes justice as necessary for peace, but asserts that peace is the end objective (27). Justice on its own calls for fairness and moral balance, whereas peace takes the relationship one step further. Alfred says that, "peace is hopeful, visionary, and forward-looking; it is not just the lack of violent conflict or rioting in the streets" $(2005,28)$. It is not enough for the police to leave us alone or for us to make recommendations within an inherently flawed system. As Alfred says, it is not enough to have a lack of injustices because Indigenous people also have to engage in an extensive healing process. A lack of injustices will allow for the decolonization process more freely, but we are also required to aggressively advance decolonization. Healing must take place traditionally while recognizing that we continue to fight for freedom. We must discover ways to decolonize without negotiating with the current injustice system. Meanwhile, our children continue to kill themselves and the state continues to advance cultural genocide on our nations. Alfred and Corntassel ask in Being Indigenous: Resurgences against Contemporary Colonialism (2005), "[H] ow can we resist further dispossession and disconnection when the effects of colonial assaults on our own existence are so pronounced and still so present in the lives of all Indigenous peoples?" (599).The answer lies in our own experiences as individuals and collectives, which give us the clearest insight into decolonization $(2005,601)$. My vision of peace looks like this: incarcerated youth have purpose in their lives, pride shines from their smiling faces and they never return to prison; their children do not know the colonial child welfare system, they only know their community, their songs, and their traditions. All Indigenous young people have a right to their culture, land and community. The rest of the Indigenous population has a responsibility to ensure this occurs. Current Condition of Youth Injustice The Injustice System in B.C. Youth injustice is governed through the Youth Criminal Justice Act (YCJA) of Canada, which replaced the Young Offenders Act (YOA) on April 1,2003. The provincial legislation in BC is the Youth Justice Act (YJA). The YCJA outlines the following principles:

- The intended purpose of the YCJA is to prevent crime by addressing circumstances underlying youth behavior, rehabilitation, reintegration and meaningful consequences for offences (emphasis added).

- "Within the limits of fair and proportional accountability," measures should be taken to respect societal values; encourage repairing relationships; "where appropriate involve the parents, the extended family, the community, and social or other agencies; respect gender, ethnic, cultural and linguistic differences, and respond to the needs of Aboriginal youth and youth with special requirements" (Youth Criminal Justice Act Canada Pocket Guide 2008, 2-4).

The Ministry of Children and Family Development (MCFD) is in charge of providing all services for children and families involved in the injustice system. Their role and mandate are as follows:

- Advance the safety and well being of children, youth and adults.

- Advance early childhood development through strategic investments.

- Advance and support a community-based system of family services that promotes innovation, equity and accountability (Ministry Overview 2008).

Youth Corrections in BC are governed by the YCJA's principles, highlighting reintegration and reduced recidivism under the least restrictive conditions possible (Youth Criminal Justice Act Canada 2008). These are lofty goals for a colonial organization based on individualistic philosophies. I will argue that the Ministry of Children and Family Development fundamentally fails in providing culturally supportive services to Indigenous youth in custody. The MCFD does not provide the services necessary to uphold the principles set out in the YCJA. For instance, the YCJA calls for services to address underlying reasons for youth behaviour. The MCFD does not address colonialism, plain and simple. The reintegration of youth is not occurring, nor is the rehabilitation of youth occurring at any sort of meaningful rate. Since reintegration and rehabilitation are the goal, any sort of meaningful punishment would reflect reintegration or rehabilitation as outcomes. As illustrated in the rates of recidivism, this is certainly not the case in BC, or anywhere else in Canada.

In addition, the colonial institutions exclude Indigenous values from their conception of "societal values," they fail to "encourage repairing relationships," and do not meet the cultural needs of Indigenous youth. The principles state that interaction with parents and community should occur "where appropriate," thus ignoring the cultural importance of a relationship between Indigenous youth and their community and family. This 
relationship to family and community, as Alfred and Corntassel (2005) point out is crucial to an Indigenous identity. The very denial of this crucial element negates Indigenous cultural needs, and serves the colonial agenda of cultural genocide. Previously, the governmental rationale was that Indian children needed a western education due to a changing economy and western culture. "It is for their own good," they would say. Currently the governmental rationale is that correctional facilities will "rehabilitate" youth into law abiding citizens. "It is for their own good", they say. Doob and Cesaroni (2004), in Responding to Youth Crime in Canada, describe the utilitarian purposes of incarceration that the Canadian government attempts to pass off as justice:

- Incapacitation; by keeping youth in custody they are unable to break the law. This proposition requires the proper identification of a criminal, which denies the fact that change is an inherent part of adolescence.

- Deterrence; incarceration will ensure that youth do not reoffend for fear of prison. This claim has proven false on account of the high levels of recidivism among youth "offenders".

- Rehabilitation; youth will be 'rehabilitated' while in custody. This claim is also false. This claim assumes that if an individual is "rehabilitated," outside influences will not be influential (229-232)

These justifications have been disproven time and time again. However, central to the argument here are the underlying assumptions about the young people involved in the justice system. Incapacitation only serves to institutionalize youth. They are separated from the rest of society and labeled as 'bad' people. This is inconsistent with traditional justice values. Deterrence implies that youth will choose to commit crime with the absence of a threat. By focusing on the negatives, youth continue to be seen as inherently deviant. Rehabilitation comes closest to dealing with the causes of youth crime; however, mainstream rehabilitation focuses on the individual, which implies that the individual alone is responsible. In traditional Indigenous justice it is understood that families and kinship networks are responsible for each other. It is also understood that rehabilitation is not an individual task; it takes an entire community. Because of this foreign system, our youth suffer from an individualized attack on their identity, and consequently, the social ills that follow.

\section{Incarcerated Indigenous Youth}

Indigenous youth are faced with extreme effects of colonization. They are also more likely to be incarcerated and spend more time incarcerated than their non-Indigenous peers. In 2004, The McCreary Centre Society surveyed youth in all three custody centers in BC (Burnaby, Victoria, and Prince
George). The purpose of the research was to profile the highest risk youth in BC in the report, Time Out II: A Profile of BC Youth in Custody. A summary of the average youth inmate, age 12 to 17, involves interaction with drug abuse, alcohol abuse, suicide, disconnection from family, involvement with the child welfare system and violence (Murphy and Chittendon $2005,5)$. Although Indigenous youth only account for 8 percent of the youth population in $\mathrm{BC}$, and 4 percent of the total Indigenous population in BC, "47\% of youth in custody said they were Aboriginal in 2004 (Murphy and Chittendon 2005,40 ). This number is astounding, but unfortunately, is representative of one of the lowest in Canada. According to A One-Day Snapshot of Aboriginal Youth in Custody: Phase II report by Latimer and Foss, British Columbia and Alberta had the lowest Aboriginal custody rates in the country. Although Indigenous youth only made up 5 percent of the total population of Canada in 2003, they made up 33 percent of the population in custody $(2004,3.1)$. The majority of these youth were placed in remand (awaiting a sentence), while more Indigenous youth than non-Indigenous youth were in secure custody (less privileges, more security) (3.3). In 2003, the median sentence length was 212 days for Indigenous youth and 182 days for non-Indigenous youth (3.6). It is obvious that although fewer youth are incarcerated in general in BC, the rate at which they are incarcerated is not only offensive, but unacceptable. In addition, "only $18 \%$ were in custody for the first time, meaning $82 \%$ of these youth had been in custody before, compared to 77\% in 2000" (Murphy and Chittendon 2005, 13). This means that more Indigenous youth are reoffending and spending subsequent amounts of time incarcerated. The determinants of incarceration are many, but stem from the effects of colonization outlined below. In BC, the incarceration rates are lower than in other provinces, but cultural refuge is not accessible. It is an inherent right that Indigenous people be able to provide cultural transmission to all their children. Cultural needs of Aboriginal inmates are recognized in legislation, yet continue to be ignored. By understanding the colonial agenda, and its effects, we can begin to piece together a decolonization strategy to reclaim our Indigenous youth.

\section{Colonialism}

\section{How This Has Affected Indigenous Identity}

Colonization serves not only to physically annihilate Indigenous peoples, but also to strip them of an Indigenous identity. The thievery of Indigenous children continues to be the colonialist's main tool. Kirmayer, Simpson, and Cargo say there are cumulative effects of colonialism on cultural identity, making it even more difficult for Indigenous youth to form a positive sense of self (2003, s.18). Jeannine Carriere (2007), in 
Promising Practices for Maintaining Identities in First Nation Adoption, has focused her research on the impacts of adoption and cultural identity loss. Carriere concludes that, "Identity was viewed by all 18 adoptees as the main loss that they experienced through adoption" (2007, 54). Similarly, Sinclair (2007) admits that despite some "success stories," we see evidence of traumatic identity crisis, psychological trauma, and behavioral problems. The Canadian government's policies continue to kill Indigenous cultures, which inhibits cultural transmission and cultural survival. Indigenous youth need cultural teachings in order to form a positive Indigenous identity and feel belonging in the world. Academics concur that identity is vital to our survival as Indigenous people (Alfred 1999; Morris 2007; Carriere 2007). A loss of Indigenous identity, through colonial policies, has devastating effects on Indigenous youth and communities.

Of the Aboriginal youth in custody, $76 \%$ have First Nations status, but most have never lived on reserve. Only 9\% have lived on a reserve for most or all of their life. Aboriginal youth in custody are more likely to have experienced disruption or trauma in their home life than their non-Aboriginal peers, including having a family member die of an overdose $(25 \%$ versus $11 \%$ ), violence ( $23 \%$ versus $9 \%$ ), or suicide ( $26 \%$ versus 10\%). And more Aboriginal youth (78\%) have been in government care than non-Aboriginal youth (69\%) (Murphy and Chittendon 2005, 40). There is an important link to be made here. Most Indigenous youth have been in care of the ministry, have experienced trauma, and are not connected to their home communities. They are lost in a colonial world. Most of the youth in custody did not feel that anyone cared for them while they were in custody. Approximately half of the youth in custody in BC in 2004 felt that someone cared about them. Approximately the same number of youth stated that a family member or parent came to visit them while in custody (Murphy and Chittendon 20054, 37). This means that half of the youth in custody are not visited by family and feel that no one cares about them. This is not alarming since 73 percent had been in care in the past year, with 46 percent having had experienced homelessness in the previous year to being incarcerated (Murphy and Chittendon 20054, 45). Indigenous youth are certainly not being supported in custody in BC, which fundamentally affects the communities they come from.

Aside from the trauma inflicted on children who are raised in non-Indigenous homes, control is taken away from community. Kirmayer, Simpson, and Cargo argue that the higher cultural continuity or 'local control' in an Indigenous community, the less likely that community will experience high rates of suicide (2003, s.18). Communities lose the possibility of cultural transmission each time a youth is lost to the colonial system. The theft and imprisonment of Indigenous youth is an attack on cultural transmission. Alfred and Corntassel (2005) would say that displacing youth is working in favor of the colonial state as a means to culturally annihilate Indigenous cultures $(2005,598)$. It is painfully obvious that it is not working in favor of the children and families in which it claims to serve and protect. Ross Gordon Green agrees, in Justice in Aboriginal Communities, that criminal law plays a pivotal role in the colonization and domination of Indigenous peoples $(1998,139)$. The approach that the system takes is individualistic and does not take into account the cultural continuity that is vital to the survival of Indigenous peoples. In addition, the effects of identity loss are compounded when Indigenous people, young or old, are not able to heal together. A healer in Returning to the Teachings said, "We heal best when we heal together” (Ross 20061996, 144). Thus, the continuation of social problems is consequential of the separation of Indigenous peoples. Kirmayer, Simpson, and Cargo also agree that the family and community must be the primary source of restoration and renewal $(2003$, s.21). This means that the institutionalization of Indigenous youth cannot continue and that Indigenous communities must wrap those youth in a blanket of cultural teachings and love. Otherwise, Indigenous youth will continue to be incarcerated.

\section{Traditional Justice and Decolonization}

To be fair, Indigenous people surely had problems with their traditional laws. Traditional laws were passed down from our ancestors, and alterations were surely accepted throughout the centuries. However, Indigenous laws were based on fundamental principles like respect. The focus was on maintaining respectful relationships in order to avoid disruptions in the community or between communities (Ross 20061996, 268). In traditional Wet'suwet'en law, it was the whole clan that put together a potlatch to pay the debt of one member who had committed an 'offence' to another nation. If someone had a grievance the chief or elders would interject, and the entire community would hold a peace-making potlatch. When this was done, peace was made. When compensation was satisfactory, the group sealed the peace with eagle down (kus: meaning eagle down literally and also 'our law'). Examples of traditional law were based on respect for everyone, and were accounted for by the entire kinship web of an individual or by the entire nation. It is these fundamental principles of interconnectedness, respect, and restoration that kept the peace between nations and within nations.

This form of social control focuses on a positive approach rather than a negative approach. The community worked together for the balance of all relationships to form a happy 
cohesive group. Maracle described the contrast with the western system of coercive force and control; "I understand that the laws were obeyed not through armed force that was alienated from the people-such as police, army etc.- but rather because the people agreed with the law. In fact they formulated them in the best interest of the community" (1996, 40-41). Indigenous knowledge and values are internalized as a societal code, whereas European laws are externally enforced by police officers, who become detectives of wrongful behavior (Little Bear 2000, 84). Of great importance was instilling children with a sense of self and importance in the community (Maracle 1996, 41). As previously discussed, the youth in need are struggling with the effects of colonization, which include alienation and a loss of Indigenous identity. Because the effects of colonialism attack all levels of being-emotional, physical, spiritual, and mental- understanding these elements is crucial for decolonization to occur. In order for this to occur, we must recognize the colonial assaults, and counter them by modeling Indigenous values and educating youth about colonization.

\section{Existing Programming}

The existing youth custody programming in $\mathrm{BC}$ is insufficient, ineffective and lacking cultural foundations. Depending on the amount of time that youth are in custody, various services are available, provided by MCFD (Youth Justice Programs 2008). After a few days or a week of being in custody youth are given permission to attend programs. Just over half of the youth in custody were invited to make decisions about their programming while in custody (Ibid, 38). This means that almost half of youth in custody were not consulted as to what programs they would like to participate in. This is incompatible to traditional valuing of autonomy and respect for young people. As stated in Youth Justice Programs (2008) programming is intended to support rehabilitation and reintegration. Such programs include; Basic Programs, like education, religious support, and recreation as well as family visits; Core Programs, like violence intervention, life skills, and substance abuse management which are meant to counteract attitudes contributing to unlawful behavior; Specialized Programs, which includes Aboriginal services, mental health services, services for female youth, and alcohol and drug counseling; and finally Reintegration Programs, which are meant to facilitate reintegration through the Intensive Support and Supervision (ISSP) program or community transition beds (Youth Justice Programs 2008, 6). Of these programs, Aboriginal services are of great concern and should be asserted as core programming. According to the federal legislation, Aboriginal cultural needs are a requirement; however, these needs are not being met. As previously discussed, most incarcerated Indigenous youth come from urban centers and foster care. This fundamentally challenges their previous opportunities to access cultural knowledge. As a result, youth are unaware of their cultural background, and or are happy to settle with whatever the custody centre will provide. Almost half of Indigenous youth said that their cultural needs were being met in custody. Nineteen percent said that their needs were not being met, and 32 percent said that they did not have cultural needs (Murphy and Chittendon 2005, 38). For many young Indigenous youth, colonization has resulted in an internalization of oppression. Alfred, in Peace, Power, Righteousness: An Indigenous Manifesto, says that, "The 'colonial mentality' is the intellectual dimension in the group of emotional and psychological pathologies associated with internalized oppression" (1999, 70). Here Alfred is discussing the co-optation of leaders into professional organizations, but the colonial mentality also permeates youths' vision of hope and cultural knowledge, resulting in internalizing the legitimacy of the injustice system and the devaluing of traditional Indigenous culture. That 32 percent of Indigenous youth reported not having cultural needs speaks to the attempted cultural genocide of Indigenous youth. The number of youth that did not access programs could also be compounded by the half of youth who are not consulted as to which programs they would like to participate in. On the other hand, Indigenous youth did make use of Aboriginal programs to some extent. In fact, of the 72 percent of Indigenous youth that participated in Aboriginal programming, 63 percent found it useful and 9 percent did not (Murphy and Chittendon 2005, 38-42). It is difficult from this data to determine what cultural programming means to Indigenous youth in custody, or what types of cultural programming exists at each youth custody centre in B.C. For some custody centers, cultural programming consists of a monthly sweat lodge ceremony and occasional arts and crafts. This is insufficient.

\section{A Framework for Reconnecting}

\section{All Elements of Being: Relationships and Mentors \\ "Before I can understand what independence is, I must break the chains that imprison me in the present, impede my understanding of the past, and blind me to the future" (Maracle 1996, 40).}

The chain that impedes Indigenous youth is the continued attack of colonialism and its effects. In order to begin the process of decolonization, the colonial system must be understood and resisted. It is not enough to assert control over Indigenous cultural transmission while participating in the oppression of youth. Indigenous people must act in accordance with traditional justice values in direct contact with youth. Otherwise, we will continue to accept colonial authority over 
the lives of our young people. Latimer and Foss report on what youth view as solutions to problems within custody and reintegration (2004, 4.3): Indigenous youth identified the need for cultural assistance in all four areas of health; mental, spiritual, physical, and emotional. They called for sweat-lodges (physical, spiritual, mental, and emotional), talking circles (emotional), smudges (spiritual), crafts (physical), pow-wows (physical), as well as singing, drumming, and dancing (physical, spiritual). The youth also requested knowledge about their history and languages from an Indigenous perspective, and more interaction with Elders (Latimer and Foss 2004, 4.3.1). These are all things that every Indigenous child has a right to. Many of our youth understand what they need to survive, and they have made a request.

Decolonizing cultural programming in custody must be based on traditional values within a political context. "Whether or not decolonization actually occurs,...depends to some extent on our ability to understand events and dynamics; to anticipate difficulties and obstacles and to ensure that all parties develop a vision, policies and strategies based on these understandings" (Taylor-Henley \& Hudson 1992, 14). Although traditional justice did not have to deal with the many effects of colonization, Indigenous people must still take the values inherent in the traditional systems and discover new ways to decolonize. Alfred (2005) argues for the decolonization of Indigenous people in Wasáse. He says Indigenous people need a "culturally rooted social movement that transforms the whole of society and a political action that seeks to remake the entire landscape of power and the relationship to reflect a truly liberated post-imperial vision" (27). Everything we do as Indigenous people is political. We must never forget the colonial relationship. Alfred asserts the need to struggle against colonialism in our totality, without compromise. Indigenous people need to engage incarcerated youth within an Indigenous framework to decolonize all elements of being.

\section{"It feels good to be Indian Today"}

Recently, a group of Indigenous young people have taken on the task of facilitating a decolonization project at a $\mathrm{BC}$ youth custody centre. This cultural programming focuses on educating youth about colonization, its effects, and how to counter those effects (decolonization). This program was founded by six Indigenous young people who have experienced the multiple effects of colonization such as displacement, adoption, foster-care, intergenerational effects of residential schools, violence, and drug and alcohol misuse, among others. These young people have taken it upon themselves to engage and support incarcerated youth where little support was available. The program is currently being piloted based on the following themes: relationship building, land, spirituality, and families. In, "Colonialism and State Dependency," Taiaiake Alfred states that, "The elements of a meaningful Indigenous existence are land, culture, and community" $(2009,26)$. He goes on to say that throughout history, spiritual and cultural regeneration have been key components in recovering dignity and self-sufficiency $(2009,7)$. Generally, the program focuses on decolonization, advocating for an Indigenous way of being in the world within a colonial context. For six weeks, two or three of the volunteers (per week) develop an interactive session to engage youth on a particular topic, using real life experiences, and to discuss decolonization initiatives. As previously stated, it is necessary to not only educate our young people about colonization, it is also necessary to model healthy relationships and behaviour creating a sense of community. Throughout the following discussion I will outline the purpose and content of the first six sessions of the program and how they are working to decolonize the youth in custody and provide an alternative discourse to internalized oppression and an unjust system. During an introduction to colonization session, facilitators outlined the effects of colonization by discussing issues such as land, families and spirituality. In order to illustrate these topics we drew upon our own experiences with residential schools, foster care, language, cultural loss, and land loss. We soon discovered, as had been expected, that each of the youth had experienced these same effects of colonization. Now, they can begin to decolonize: to acknowledge the systems of domination and oppression that rule our lives and land as Indigenous Peoples. It is only when we understand the system that has affected us that we can begin to unravel the levels of oppression that can lead to self-hate and destruction. When we educate youth about what has happened to us and why, the only question left is: What do we do about it now? This engages youth in decolonizing their own lives in whatever capacity they can. We have asked them to identify their colonial experiences through media images, and to also identify an act or way of thinking that counters these experiences of colonization. By involving Indigenous volunteers who have experienced many of these same things, we lead by example. By engaging youth on these topics we begin to model the values which have been taken away from us; we begin to rebuild those relationships and act like a traditional community would have. We must recognize the colonial assaults that have landed Indigenous youth in this position, we must recognize our political positions as Indigenous nations and then we must take control of the cultural transmission to our youth in custody in order for decolonization to occur. We must achieve this goal for the survival of incarcerated Indigenous youth, beginning with respectful relationships. 


\section{Relationships}

Interconnectedness necessarily requires respectful relationships. It is these relationships that must be rebuilt upon traditional cultural foundations in order for communities to thrive. Youth have called for relationships with Elders and community members who they have something in common with. Similarly, Alfred and Corntassel consider relationships to be central to an Indigenous identity. They see relationships as, "the spiritual and cultural foundations of Indigenous peoples" $(2005,609)$. In order to survive we must strengthen these relationships and nurture to health our young people that have fallen, so that they can grow up to know what freedom is. In The Book of Elders, by Johnson (1994), Janet McCloud offers her own knowledge about young ones. She tells Johnson that if Indigenous people want their children to have a better future, they had better remember that children learn by imitating, thus we must all be the teachers. If Indigenous people want the next generation to resist the colonial system and to live healthy lives, we must show them what that looks like (Johnson 1994, 62). Let us not assume the strength of the colonial system. Let us focus on our own strengths as Indigenous people. These relationships must nurture all elements of being; mental, physical, emotional and physical.

The facilitators invited local Elders to participate in a relationship building session. It is critical that we model appropriate protocol to the youth, as many of them, including volunteers, are not residing on their traditional territory and have experienced displacement. In addition, inviting Elders to the session bridges the gap between cultural knowledge holders and youth. It is important for youth the see the intergenerational effects that colonization has had, and the caring that multiple generations have for their well being. We also took this time to allow the Elders to talk about their culture and experiences on the territory and/or with colonization. The purpose of this initial session was to become comfortable with youth and to open the doors of communication. The elders brought a drum, and songs were sung. The session ended with a "check out" round that invited the youth to say one word that described the engagement we had just experienced. One youth said, "It feels good to be Indian today's a good day to be Indian." This type of engagement is critical in empowering the youth to see the many conditions of colonization that have contributed to their experiences.

\section{Families}

Traditional justice was effective because each individual was socialized with the values, customs and philosophies of the group. These values served as a means of social control. The laws were the practical application of the philosophy and values of Indigenous peoples (Little Bear 2000, 79). Traditionally, kinship ties were the locus of social control, which meant that these interconnected relationships provided strength among the group. The breakdown of families due to the continued theft of children must be considered in any decolonization project. Little Bear (2000) acknowledges the values of sharing and strength as ways to sustain balance among the group. Today, many of the youth in custody have come from the foster care system or have been impacted by residential schools or the sixties scoop. By educating young people on the effects of colonization on our families they are less likely to internalize their experiences. As previously discussed, the effects of colonization on youth in custody are compounded by the injustice system and perpetuate internalized anger, shame, and the oppression of each other. In addition, by focusing on families, we can educate youth on the effects of residential schools and the colonial legislation that often lands them in foster care. A critical part of this education about Indigenous families is to provide youth with an alternative. While it is critical to educate youth about colonial assaults on our families, it is also critical to provide them with a sense of hope. Many of our young people do not see an alternative way of living and have only known the worst effects of colonization. By providing them with a glimpse of a healthy way of life as an Indigenous person, they will be provided with hope for breaking the cycle. To do this, the facilitators often use their own life stories as examples of how we, as young Indigenous people, are able to break the cycles of abuse our families have suffered. Youth have expressed the need to connect with people that understand their struggles. One youth says, "I would rather go somewhere to talk to someone that I can trust, the certificate or degree doesn't matter, I would rather someone who will understand" (qtd. in Latimer and Foss 2004, 4.3.2). Youth assert their desire to engage with positive influences and people who can understand their experiences. Youth have stated their needs for Indigenous support, including spirituality.

\section{Spirituality}

Indigenous youth also stated their need for spirituality (Latimer and Foss 2004, 4.3.1). Through relationships with youth, spiritual practices can be reintroduced and strengthened. Alfred identifies spirituality as the root of the struggle. Without grounding in a strong spiritual connectedness successful recovery of our territories and political power will be meaningless to the survival of our people $(2005,38)$. Traditional spiritual practices will strengthen the spirituality that is necessary for a balanced life. "These traditions were displaced and actively suppressed by successive generations of Euro-Canadian missionaries, governments and professionals. Revitalizing these traditions therefore reconnects contemporary Aboriginal peoples to their 
historical traditions and mobilizes rituals and practices that may promote community solidarity" (Kirmayer et al. 2003, s.16). It is vital that each and every youth have the opportunity for this spirituality. Indigenous young people have a right to their spiritual practices, and we have a responsibility to provide access to them.

It is critical that we spend an entire session on how our spirituality has been affected by colonization and explore ways that we can decolonize this aspect of our lives. This can begin by discussing the role that spirituality plays within a traditional way of being. For example, spirituality has become disconnected from secular living and therefore also disconnects individuals from other life forms. This aspect of colonization impacts our relationships to the spirit world as well as our relationships to each other and most importantly land. It is important to demystify spirituality for youth. It is not a question of whether or not they will understand what spirituality is, but that spirituality often becomes seen as religion instead of a way of life. A good forum to discuss these issues is through story telling. By engaging youth through a story, whether this is a real life story or in the form of poetry, youth can begin to see how spirituality is situated within the context of every day life. It is necessary to unpack the differences between religion and spirituality so that spirituality does not remain a mystifying concept left to shamans and Elders. It is necessary to learn why our spiritual practices have been lost, but also to have the courage to reclaim a way of life that has sustained not only humans, but all of creation since time began. For Indigenous peoples, spirituality was integrated into the culture and relationship to the land; it is necessary for youth to understand this concept and how our way of life is necessary tied to our territory.

\section{Land and Physical Impacts}

The physical effects of colonization that Indigenous youth have experienced are reflected in their health and the health of our homelands. The two are intricately interconnected. All of the above themes relate back to our physicality and land. It is not enough that we should physically survive and have control over our land base. As Alfred (2009) asserts, our disconnection from land has caused Indigenous people to become physically unhealthy and dependent on the state. The importance of land must be identified as one of the most important aspects of Indigenous identity. One of the major challenges that youth in custody face are that most come from urban environments and may not have an existing relationship with the land. Although spirituality occurs within Indigenous peoples themselves, culture is very much based within the context of homelands. Sean Kicummah Teuton, in Red Land, Red Power, asserts that without land it is difficult to hold the body of knowledge used to maintain cultural identity (2008, 44). This also includes language, and the importance of coupling language with homelands. This means that it is critical for Indigenous peoples to secure and protect their homelands in order for culture and language to survive. Indigenous peoples have lived in harmony with the land and its beings since time began, which has necessarily impacted our way of knowing and living. Therefore, land and culture are inseparable. Not only is it critical that Indigenous young people understand the negative affects caused by our displacement from our lands, and the resulting anomie, but we must also provide them with a sense of reconnecting. If young people do not have an investment in the land, they would have no desire to maintain it. It is critical that youth understand the role that land has played from the beginning of colonial contact to the current context. For instance, land is the prized possession of the colonizer. In contrast, Indigenous families have particular roles in caring for the land and keeping humans in harmony and balance with our territories. Most importantly, land must be seen as an interconnected aspect of all Indigenous life. Without it we would all cease to exist. It is all at once, life giving and uniting. Despite our languages, spiritual practices, and protocols, all Indigenous peoples share a deep relationship to land, and have experienced the same effects of displacement from that land. This knowledge can give youth the hope and determination necessary to walk each day towards reclaiming not only our homelands, but the relationship to that land that has sustained us since time began.

\section{Conclusion}

There are thousands of incarcerated Indigenous youth in Canada. BC has nearly the lowest incarceration rates, yet our children continue to be stolen at heartbreaking rates. It is imperative that Indigenous people struggle against the colonial institutions that continue the thievery of our children. There are countless initiatives and strategies to keep our Indigenous youth out of correctional facilities. This is necessary, but also, not enough. Traditional justice worked because people were socialized with Indigenous values and beliefs. The colonial injustice system not only undermines these beliefs, but also leaves youth without a positive Indigenous identity. Not only are Indigenous youth suffering the worst effects of colonization, but they are further degraded in custody centers. We must not accept the degradation of our youth in systems opposed to Indigenous values and philosophies. Our people are struggling in the realm of self-determination, child-welfare- as a great concern- and land disputes with the provincial and federal governments. I realize that we have been worn thin in many areas, but this must not impede our struggle; it never has. Indigenous people have always resisted the thievery of children, 
and have always continued the struggle against colonial domination. We are getting stronger. Issues of child thievery must continue to be attacked at all levels. Prevention is ideal, but we must remember those who have fallen. The families that have already lost their children, and the children and communities that are suffering the loss. We cannot abandon those young people in colonial institutions; it is inconsistent with Indigenous values and teachings. Indigenous young people need to be educated about their history through direct contact with mentors and Elders. This knowledge is not reaching them through mainstream education, and they are unlikely to have access to such knowledge holders given the high percentage of youth in care or on the streets. Awareness of the colonial condition and mindset will allow for the mental health of Indigenous youth and the decolonization process to strengthen. What is needed is a holistic healing and educative program. How many times have we heard people say, "It takes a community to raise a child?" Based on value systems of interconnectedness we must work towards an Indigenous framework based on Indigenous values. This education must include knowledge about our histories and language as well as spiritual, physical, and emotional support. Most Indigenous people agree that mental, physical, emotional and spiritual realms must be balanced for a healthy Indigenous identity. This must occur in order to strengthen Indigenous people in the struggle for peace and freedom. We all need to call back the youth; the effects of colonization have been weighing on them for too long.

By engaging traditional principles, Indigenous peoples must take control of cultural programming in youth correctional facilities. Relationships based on respect can be the vehicle for the transmission of spiritual health, mental health, physical health, and emotional health. Programs initiated by Indigenous people who have experienced these same effects of colonization are necessary. Every youth in custody has a right to relationships built on respect and cultural values. Youth have requested this and know they need them to survive as Indigenous people. Every Indigenous person matters to the strength of the whole, and through experience, we will learn more and more ways to resist, and we will achieve freedom for all Indigenous young people. As communities of Indigenous people, we will gain strength through our relationships and we will strengthen our emotional, spiritual, physical, and mental selves so that we can all be whole.

Change Happens one Warrior at a Time- our people must reconstitute the mentoring and learning-teachings relationships that foster real and meaningful human development and community solidarity. The Movement toward decolonization and regeneration will emanate from transformations achieved by direct-guided experience in small, personal, groups and oneon-one mentoring towards a new path (Alfred and Corntassel 2005, 613).

\section{References}

Alfred, Taiaiake. (2009). Colonialism and State Dependency. Prepared for the National Aboriginal Health Organization Project Communities in Crisis.

Alfred, Taiaiake. (2005). Wasáse: Indigenous Pathways of Action and Freedom. Peterborough, ON: Broadview Press. Alfred, Taiaiake. 1999. Peace, Power, Righteousness: an indigenous manifesto. Don Mills: Oxford University Press.

Alfred, Taiaiake, and Jeff Corntassel. (2005). Being Indigenous: Resurgences against Contemporary Colonialism. Retrieved November 10, 2009 from http://www.corntassel.net/being_indigenous.pdf.

Carriere, Jeannine. (2007). "Promising Practice for Maintaining Identities in First Nation Adoption." First Peoples Child \& Family Review, 3(1): 46-64. Retrieved from http://www.fncfcs.com/pubs/vol3numl/ Carriere_pp46.pdf.

Doob, Anthony, N. and Carla Cesaroni. (2004). Responding to Youth Crime in Canada. Toronto: University of Toronto Press.

Green, Ross Gordon. (1998). Justice in Aboriginal Communities: Sentencing Alternatives. Saskatoon: Purich Publications.

Johnson, Sandy. (1994). The Book of Elders: The Life Stories of Great American Indians. New York: Harper Collins Publishers.

Kirmayer, Laurence, Cory Simpson and Margaret Cargo. (2003). "Healing Traditions: culture, community, and mental health promotion with Canadian Aboriginal Peoples." Australian Psychiatry, 11: s15-s23.

Latimer, Jeff. And Laura Casey Foss. (2004). A One-Day Snapshot of Aboriginal Youth in Custody in Canada: Phase II. March 14, 2008. Department of Justice Canada. Accessed on November 28, 2008 at http://www.justice.gc.ca/eng/pi/rs/rep-rap/2004/yj2-ji2/yj2.pdf.

Little Bear, Leroy. 2000. "Jagged Worldviews Colliding." In Battiste, Marie ed. Reclaiming Indigenous Voice and Vision. Vancouver: UBC Press.

Maracle, Lee. 1996. I Am Woman: A Native Perspective on Sociology and Feminism. Vancouver: Press Gang Publishers.

Ministry Overview. 2008. Ministry of Children and Family Development. Accessed November 21, 2008 at http://www.mcf.gov.bc.ca/about_us/ overview.htm

Morris, Kristine. 2007."(A Literature Review) Re-examining issues behind the loss of family and cultural and the impact on Aboriginal youth suicide rates." First Peoples Child \& $\quad$ Family Review, 3(1): 133-142.

Murphy, Aileen, Minda Chittenden, \& The McCreary Centre Society (2005). Time Out II: A Profile of BC Youth in Custody. Vancouver, $B C$. The McCreary Centre Society.

Ross, Rupert. 2006. Returning to the Teachings: Exploring Aboriginal Justice. Toronto: Penguin Canada.

Taylor-Henley, Sharon, and Peter Hudson. 1992. "Aboriginal SelfGovernment and Social Services: First Nations: Provincial Relationships." Canadian Public Policy, 18: 13-26. 


\section{Youth Custody: Exercising our Rights and Responsibilities to Indigenous Youth}

Teuton, Sean Kicummah. 2008. "Embodying Lands: Somatic Place in N.

Scott Momaday's House Made of Dawn." In Red Land, Red Power:

Grounding Knowledge in the American Indian Novel. Durham: Duke

University Press.

Ministry of Children and Family Development. (2008). Youth Justice

Programs: Vancouver Island. Victoria, BC. The Author. Accessed

November 20, 2008 at http://www.mcf.gov.bc.ca/youth_justice/pdf/ youth_justice_booklet07.pdf

Ministry of Children and Family Development. (2004). Youth Criminal Justice Act Canada Pocket Guide (2nd Edition). Accessed November 20, 2008 at http://www.ag.gov.bc.ca/public/ycja/pocket-guide.pdf. 